\title{
Statistical methods to study adaptability of barley genotypes evaluated under multi environment trials
}

\author{
Ajay Verma*, V. Kumar, A.S. Kharab and G.P. Singh \\ Statistics and Computer Center, ICAR- Indian Institute of Wheat and Barley Research, Karnal (Haryana) India \\ (Email : verma.dwr@gmail.com)
}

\begin{abstract}
Genotypes G5, G8, G3, G21 and G18 had achieved higher yields besides $b_{\mathrm{i}}>1.0$. G21 and G3 identified as appropriate one, because had higher yield value than the mean, $b_{i}$ values near 1.0 and low $S_{\mathrm{di}^{2}}$. Lower values $\left(\mathrm{W}_{\mathrm{i}}^{2}\right)$ resulted for G12, G5, G2, G21 while higher for G5, G3 and G14. Genotypes G12 followed by G2, G20, and G7 had the smallest environmental variance ( $\mathrm{S}_{\mathrm{xi}}^{2}$ ). Smaller values of $\left(\mathrm{CV}_{\mathrm{i}}\right)$ considered G12, G2, G20, and G10 of stable performance. $\sigma_{\mathrm{i}}^{2}$ measure pointed out G12, G7 and G2 with smallest values. Desirable lower $P_{i}$ values reflected by G18, G5, G21, and G4 while GAI values identified G18, G11, G4 G10 as desirable genotypes. $S_{i}^{(1)}$ and $S_{i}^{(2)}$ showed lower values of G12, G2 and G7 genotypes. Significant tests of $S_{i}^{(1)}$ and $S_{i}^{(2)}$ proved the highly significant difference in ranks among the 21 genotypes grown in 8 environments. Genotypes G12, G2, and G7 had the lower $S_{i}^{(3)}$ and $\mathrm{S}_{i}^{(6)}$ values. Yield of genotypes had significant negative correlation with $\mathrm{b}_{\mathrm{i}}, \mathrm{S}_{\mathrm{i}}^{(2)}, \mathrm{S}_{\mathrm{i}}^{(3)}, \mathrm{S}_{\mathrm{i}}^{\left({ }^{(6)}\right.}, \mathrm{NP}_{\mathrm{i}}^{(2)}, \mathrm{NP}_{\mathrm{i}}^{(3)}, \mathrm{NP}_{\mathrm{i}}^{(4)}$ and significant positive correlation with GAI, $\mathrm{P}_{\mathrm{i}}$ and Rank Sum. Hierarchical cluster analysis classified genotypes into three clusters as largest cluster included genotypes with more than average yield along with high yielders G18, G11, G3, G5, G21 and unstable performance indicated by non parametric measures. Biplot analysis while considering first two significant principal components grouped the parametric and non parametric measures into four groups. The smaller group consisted of $b_{i}$ and $S_{\text {di }}^{2}$ and adjacent to group of non parametric measures $\mathrm{S}_{\mathrm{i}}^{(2)}, \mathrm{S}_{\mathrm{i}}^{(6)}, \mathrm{NP}_{\mathrm{i}}^{(2)}, \mathrm{NP}_{\mathrm{i}}^{(3)}$ and $\mathrm{NP}_{\mathrm{i}}^{(4)}$.
\end{abstract}

Key Words : Barley, Parametric, Non-parametric measures, Biplot analysis, Hierarchical clustering

View Point Article : Verma, Ajay, Kumar, V., Kharab, A.S. and Singh, G.P. (2018). Statistical methods to study adaptability of barley genotypes evaluated under multi environment trials. Internat. J. agric. Sci., 14 (2) : 283-291, DOI:10.15740/HAS/IJAS/14.2/283-291. Copyright@ 2018: Hind Agri-Horticultural Society.

Article History : Received : 18.01.2018; Revised : 16.04.2018; Accepted : 02.05.2018

\footnotetext{
* Author for correspondence:
} 